\section{BMJ Paediatrics Open}

\title{
How are behavioural interventions delivered to children (5-11 years old): a systematic mapping review
}

Amberly Brigden (D) , ${ }^{1}$ Roxanne Morin Parslow, ${ }^{1}$ Catherine Linney, ${ }^{1}$ Nina Higson-Sweeney, ${ }^{2}$ Rebecca Read, ${ }^{2}$ Maria Loades, ${ }^{1,2}$ Anna Davies, ${ }^{1}$ Sarah Stoll, ${ }^{1}$ Lucy Beasant, ${ }^{1}$ Richard Morris, ${ }^{3}$ Siyan Ye, ${ }^{1}$ Esther Crawley (1) ${ }^{1}$

To cite: Brigden A, Parslow RM, Linney C, et al. How are behavioural interventions delivered to children (5-11 years old): a systematic mapping review. BMJ Paediatrics Open 2019;3:e000543. doi:10.1136/ bmjpo-2019-000543

- Additional material is published online only. To view please visit the journal online (http://dx.doi.org/10.1136/ bmjpo-2019-000543).

Received 18 June 2019 Revised 11 October 2019 Accepted 18 0ctober 2019
Check for updates

(c) Author(s) (or their employer(s)) 2019. Re-use permitted under CC BY-NC. No commercial re-use. See rights and permissions. Published by BMJ

${ }^{1}$ Centre for Academic Child Health, Bristol Medical School, University of Bristol, Bristol, UK ${ }^{2}$ Department of Psychology, University of Bath, Bath, UK ${ }^{3}$ Bristol Medical School, University of Bristol, Bristol, UK

Correspondence to Amberly Brigden; amberly. brigden@bristol.ac.uk

\section{ABSTRACT}

Context Behavioural interventions are used to prevent, manage and treat a wide variety of conditions including obesity, diabetes, chronic pain, asthma and emotional difficulties. There has been inadequate attention to the delivery of behavioural interventions to younger children (5-11 years old).

Objective Our objectives were to describe the characteristics of behavioural interventions for children aged $5-11$ years.

Data sources We searched five databases: CINAHL, EMBASE, PsycINF0, MEDLINE and Cochrane Library, from January 2005 to August 2019.

Study selection The inclusion criteria were (1) children aged 5-11, (2) cognitive and/or behavioural interventions, (3) randomised controlled trials and (4) 2005 onward. Two researchers independently identified studies for inclusion.

Data extraction Two researchers independently extracted data from eligible papers.

Results The search identified 10541 papers. We extracted information on 117 interventions (from 152 papers). Many of the interventions were categorised as complex. This was particularly true for clinical populations; $78.7 \%$ were delivered to both the child and parent, and $33.9 \%$ took place across multiple settings, typically health and school settings. Most (70.9\%) were 'First Wave' (behavioural) interventions, and few (4.3\%) were 'Third Wave' (characterised by metacognition, acceptance and mindfulness). Thirty-nine per cent used interactive techniques (play, arts, story and/or games). Purely digital and paper-based interventions were rare, but around a third used these tools as supplements to face-face delivery. There were differences in interventions for younger (5-7 years) and older (8-11 years) children. Conclusions Interventions designed and delivered to children should be developmentally sensitive. This review highlights characteristics of interventions delivered to children 5-11 years old: the involvement of the child's parent, using behavioural (rather than cognitive) modalities, using interactive techniques and some interventions were delivered across multiple settings.

\section{INTRODUCTION}

Health in childhood lays the foundations for health across the lifespan. ${ }^{1-7}$ Behavioural interventions are used to prevent, manage

\section{What is known about the subject?}

Behavioural interventions can be used to prevent, treat and manage a range of health conditions. Children 5-11 years old have distinct physical, emotional, social and cognitive developmental characteristics. These developmental differences should be considered when designing interventions for children.

\section{What this study adds?}

This review highlights intervention characteristics to consider when designing and delivering interventions for children 5-11 years old. Interventions for children aged $5-11$ years typically involve parents, span multiple settings, use a 'First Wave' behavioural modality and integrate interactive techniques (play, arts, story and/or game-based techniques).

and treat a range of health conditions in childhood. Behavioural interventions targeting lifestyle behaviours, such as a healthy eating and physical activity, ${ }^{8}$ can prevent obesity, dental problems and osteoporosis. Behavioural interventions can support the management of long-term health conditions such as attention deficit hyperactivity disorder (ADHD), asthma, diabetes, chronic pain and cystic fibrosis, by promoting medication adherence, monitoring of health markers (eg, insulin and blood pressure $)^{9}$ and engagement in condition-specific health behaviours. In some cases, behavioural intervention can be used to treat a condition, as in depression and anxiety, where the treatments tackle the maladaptive cognitions and behaviours that underlie the disorder. ${ }^{10}$

Behavioural interventions ('First Wave') are based on the theory that all behaviours are learnt (through classical and operant conditioning $)^{11}$ and that maladaptive behaviours can be changed using principles such as 
reinforcement, modelling, graded tasks and habit formation. ${ }^{12}$ Cognitive-behavioural (CBT, 'Second Wave') interventions are based on the principle that thoughts, feelings, physical sensations and actions are interconnected; individuals are supported to identify negative/unhelpful patterns in their cognitions, emotions, behaviours, physical sensations and supported to adopt more adaptive patterns. ${ }^{13}$ The 'Third Wave' of cognitivebehavioural interventions are characterised by techniques such as metacognition, acceptance, mindfulness, compassion and spirituality. ${ }^{11}$

While behavioural interventions are commonly used in adolescent populations, less is known about the appropriate or effective ways to deliver interventions in younger, primary-school-aged children (5-11 years). Inadequate attention has been paid to designing/adapting interventions for the specific developmental stage of this age group $^{1415}$ and comparatively fewer trials evaluating them in this younger age group. ${ }^{15-17}$

Theory should be used when developing interventions ${ }^{18-21}$; when designing interventions for children, this means considering development theory. ${ }^{1422} 22$ Younger children have distinct physical, emotional, social and cognitive developmental characteristics. Younger children (under seven) are pre-logical and their thinking is dominated by perception. From the age of seven onward, children start to think logically, but until age 12, they are still limited to concrete rather than abstract thought processes. ${ }^{13}$ In line with cognitive development, children hold more basic beliefs about illness ("When you leave the window open, your blankets get cold which can make you a little bit sick") and magical thinking about illness. ${ }^{23}$ Children are more reliant on caregivers. Parents/carers are typically the gatekeepers to recognising their child's health needs, accessing services and implementing/overseeing health interventions. ${ }^{24}$ Children are also more reliant on caregivers at school, relying on teachers to support the management of their health condition. ${ }^{25}$

A better understanding of the characteristics of behavioural interventions for children will be helpful for researchers developing and evaluating interventions, as well as clinicians implementing them. Mapping reviews are useful when synthesising information from a broad field of study, covering a large volume of literature. ${ }^{26}$ This study aims to 'map' behavioural interventions designed for younger primary-school-aged children (5-11 years old) to describe the way they are delivered to this age group in terms of recipients, modality, setting, mode and techniques of delivery.

\section{METHODS \\ Design}

We carried out a mapping review to answer the question: "how are behavioural interventions delivered to children aged 5-11?".

\section{Search strategy}

The search strategy was developed with a University of Bristol data specialist. It included keywords and $\mathrm{MeSH}$ headings for (1) children aged 5-11, (2) cognitive and/ or behavioural interventions, (3) randomised controlled

\begin{tabular}{|c|c|c|}
\hline & Inclusion & Exclusion \\
\hline $\begin{array}{l}\text { Participants/ } \\
\text { population }\end{array}$ & $\begin{array}{l}\text { Interventions designed for children aged } \\
\text { between } 5 \text { and } 11 \text { years at entry to study } \\
\text { Interventions delivered directly to the child and } \\
\text { indirectly (ie, delivered by a proxy parent) } \\
\text { All conditions/diseases or health behaviours }\end{array}$ & $\begin{array}{l}\text { Populations including children aged } 5-11 \text { years, but also } \\
\text { spanning a wider age range (eg, } 5-16 \text { years) } \\
\text { Participants with developmental delays as defined } \\
\text { by the ICD }-10 .^{86} \text { This review aimed to look at how } \\
\text { interventions were delivered to the developmental stages } \\
\text { of childhood (5-11 years). Children } 5 \text { to } 11 \text { years old with } \\
\text { developmental delays would not be at a typical } 5-11 \text { year } \\
\text { developmental stage }\end{array}$ \\
\hline Intervention & $\begin{array}{l}\text { Any behavioural intervention (First, Second or } \\
\text { Third Wave }{ }^{11} \text { ) aiming to change behaviour with } \\
\text { a view to changing health outcomes or health } \\
\text { behaviours (physical and mental health) }\end{array}$ & $\begin{array}{l}\text { Interventions that were not cognitive and/or behavioural } \\
\text { (eg, surgery, medications etc) }\end{array}$ \\
\hline Context & Any settings & Not restricted by setting \\
\hline Time & $\begin{array}{l}\text { From } 2005 \text { to } 2019 \text {. The UK's Increasing Access } \\
\text { to Psychological Therapies initiative was } \\
\text { established in } 2005 \text {; this was characterised by } \\
\text { an expansion in the provision and evaluation of } \\
\text { psychological therapies, largely } \mathrm{CBT}^{23}\end{array}$ & Any study prior to the year 2005 \\
\hline Study type & $\begin{array}{l}\text { RCTs } \\
\text { Published in peer-reviewed journals and } \\
\text { available in English }\end{array}$ & $\begin{array}{l}\text { Studies that were not RCTs, eg, observational cohort } \\
\text { studies and case reports }\end{array}$ \\
\hline
\end{tabular}

We use the term 'parent' to refer to the primary caregiver/caregivers within the home.

$\mathrm{CBT}$, cognitive-behavioural therapy; $\mathrm{RCT}$, randomised controlled trial. 
trials (RCTs) and (4) 2005 to present (online supplementy appendix A). The search was carried out on relevant databases: CINAHL, EMBASE, PsycINFO, MEDLINE and the Cochrane Library (August 2019).

\section{Screening}

Titles and abstracts (stage one) and full-text papers (stage two) were double screened against inclusion/exclusion criteria (table 1) using the data management platform Covidence. ${ }^{27}$ Reasons for exclusion were recorded at stage two. Discrepancies at both stages were discussed and resolved in meetings by reviewers. If the full text did not contain the information needed, we made two attempts to contact authors by email. If information was not provided, the study was excluded.

\section{Data extraction and synthesis}

Data were independently extracted by two researchers and conflicts resolved in regular meetings. We extracted characteristics of the population and intervention as described in table 2. We created categories for these based on existing taxonomies/coding systems or through an inductive process.

\section{Quality assessment/risk of bias}

We believe that there are no quality assessment tools for mapping review methodology. ${ }^{26}$ Further, given the large

Table 2 Data extraction

\section{Categories}

$\begin{array}{ll}\text { Population } & \text { Children's ages were grouped by UK school 'Key Stage' categories }{ }^{79} \text { : } \\ \text { Age } & 5-7 \text { years, corresponding to Key Stage 1 (KS1) } \\ & \text { - Including both KS1 and KS2 participants } \\ \text { Population } & \text { Participants were grouped into clinical, at-risk and healthy (based on the coding system indicated, selective, } \\ & \text { universal) } \\ & \text { Clinical; those identified as have a disease/disorder } \\ & \text { At-risk; those identified as at risk of a health condition } \\ & \text { Healthy; universal interventions targeting a whole population groups } \\ \text { Condition/behaviour } & \text { The condition or behaviour that the intervention was designed to target was grouped into } \\ & \text { Lifestyle; day-to-day health behaviours such as diet, exercise, smoking } \\ & \text { Neurodevelopmental } \\ & \text { Social-emotional-behavioural } \\ & \text { Physical symptom management/treatment }\end{array}$

\begin{tabular}{|c|c|}
\hline Intervention & \\
\hline Recipients & $\begin{array}{l}\text { Codes were used to note whether the intervention was delivered directly to the child, via a parent-proxy or } \\
\text { both }\end{array}$ \\
\hline Modality & $\begin{array}{l}\text { The type of intervention (modality) was coded as either a First, Second or Third Wave }{ }^{11} \text { behavioural } \\
\text { intervention }\end{array}$ \\
\hline Setting & $\begin{array}{l}\text { Categories for setting were inductively developed: } \\
\text { School } \\
\text { Clinical/health } \\
\text { Community }\end{array}$ \\
\hline Mode of delivery & $\begin{array}{l}\text { Categorised in accordance with elements of the mode of delivery taxonomy }{ }^{78} \text { : } \\
\text { Face-to-face. If the intervention was face-face, we documented whether this was delivered on an } \\
\text { individual basis or in group setting } \\
\text { Paper based } \\
\text { Digital }\end{array}$ \\
\hline Techniques of delivery & $\begin{array}{l}\text { Inductive categories were developed for techniques of delivery: } \\
\text { Interactive techniques: play, arts, story and/or game-based techniques } \\
\text { Reward-based techniques }\end{array}$ \\
\hline Complexity & Interventions were classed as complex if they contained multiple components ${ }^{76}$ \\
\hline Effectiveness & $\begin{array}{l}\text { To provide an overview of the effectiveness of interventions, the effect of the intervention on the specified } \\
\text { primary outcome was extracted. To identify the primary outcome, the original paper, any published protocols } \\
\text { and trial registries were reviewed. If a primary outcome was specified, the following categories were used: } \\
\text { 'Promising', if there was improvement in the primary outcome in the intervention group compared with the } \\
\text { control, as reported by the authors } \\
\text { 'Not promising', if there was no improvement in the primary outcome in the intervention group compared } \\
\text { with the control, as reported by the authors } \\
\text { If no primary outcome was specified, we categorised this as } \\
\text { 'Unable to assess effectiveness' }\end{array}$ \\
\hline
\end{tabular}


volume of studies in this review, it was not feasible to carry out quality assessment.

\section{Patient and public involvement}

We did not involve patients or the public in our work.

\section{RESULTS}

The search identified 10541 papers. In total, 5583 were excluded at the title and abstract review stage, and 1975 were excluded at the full-text review stage. The most common reasons for exclusion at full text were wrong age $(n=1070)$, not an RCT $(n=577)$ and wrong paper type (protocol, abstract, presentation etc; $n=206$ ). One hundred and fifty-two papers were eligible for the mapping review. The PRISMA diagram ${ }^{28}$ is displayed in figure 1.

Of the 152 citations, 21 interventions were described across two or more papers, and eight papers included two different active interventions. Therefore, in total we extracted data from 117 interventions.

\section{Population characteristics}

Populations: 56 interventions $(47.9 \%)$ targeted clinical populations; 41 (35.0\%) targeted healthy populations; 19 $(16.2 \%)$ targeted at-risk populations. One intervention was for healthy population, with a more intensive component for a subset of at-risk participants. Figure 2 displays the characteristics of intervention for each population.

Age: 72 interventions $(61.5 \%)$ included both younger (5-7years old) and older (8-11years old) children. Twenty-eight $(23.9 \%)$ included older children only and
$17(14.5 \%)$ included younger children only. Figure 3 displays the characteristics of intervention for these different age groups.

Condition/behaviour. 54 interventions $(46.2 \%)$ targeted lifestyle behaviours (diet, physical activity, dental care, hand washing, injury prevention, sexual health, substance use); $41(35.0 \%)$ were for social-emotional-behavioural presentations (anxiety, conduct/opposition disorder, trauma, depression, behavioural problems); 14 (12.0\%) were for neurodevelopmental disorders (ADHD); 8 $(6.8 \%)$ were for physical symptom management/treatment (bladder/bowel dysfunction, asthma, cystic fibrosis, pain, sleep disorder).

\section{Intervention characteristics}

Recipients: 75 interventions $(64.1 \%)$ involved parents. Of these, $66(88 \%)$ involved both parent and child, and 9 (12\%) were parent only. Considering the younger children (5-7years old), all interventions for clinical populations included parents. None of the interventions for children 8-11 years old were delivered without the child (figure 3). Fifty-nine interventions $(78.7 \%)$ for clinical and at-risk populations involved parents.

Six of the RCTs were designed to compare the effectiveness of child versus parent involvement; exploring parents exclusively versus parents and child ${ }^{29-31}$ or child exclusively versus child and parent. ${ }^{32-34}$

In some cases, a rationale for including parents was not provided. Where a rationale was provided, this included a theoretical rationale (social cognitive and parenting theories) ${ }^{32} 35-37$; the role of parents in controlling the child's

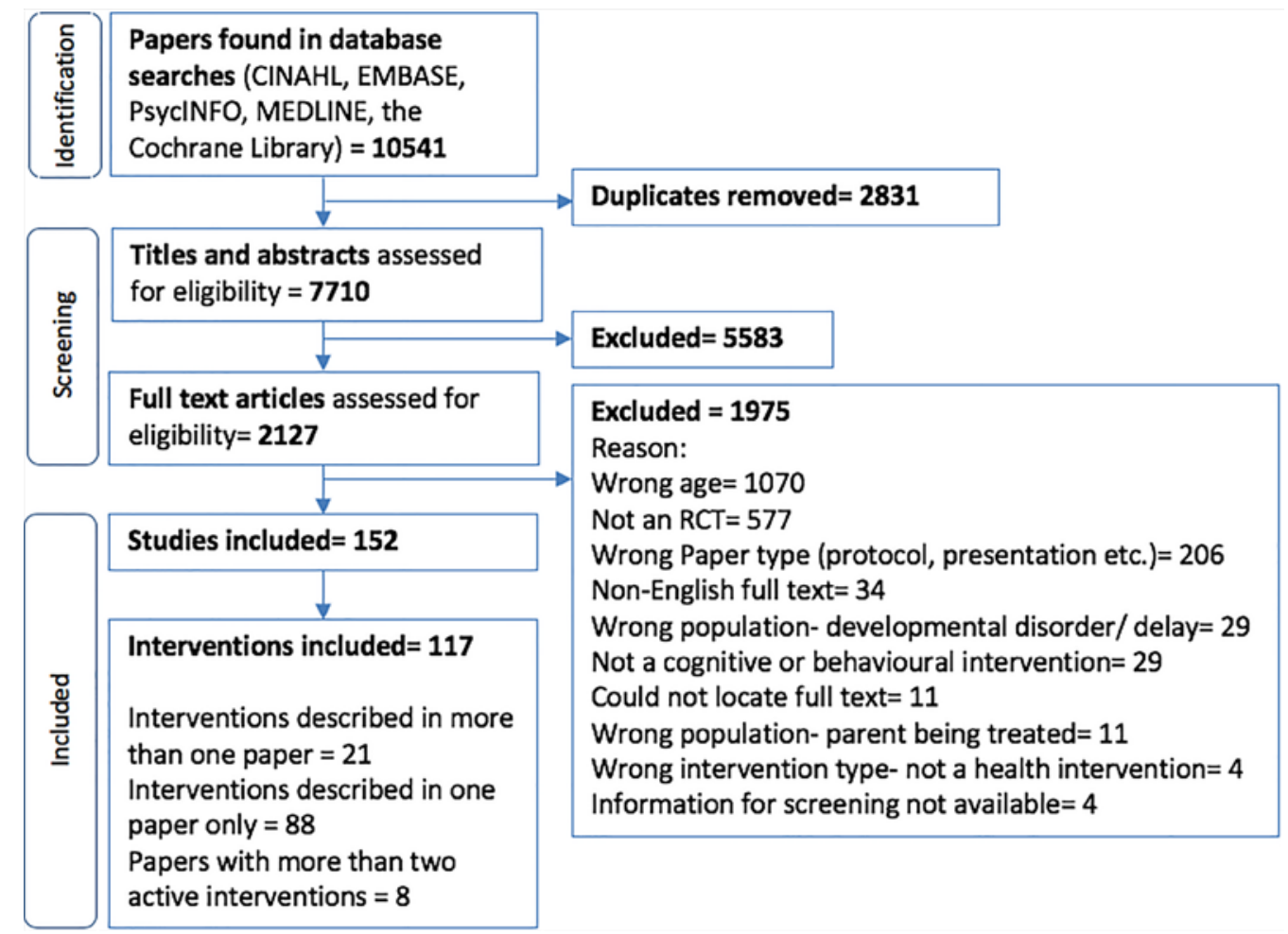

Figure 1 PRISMA diagram of study screening. RCT, randomised controlled trial. 


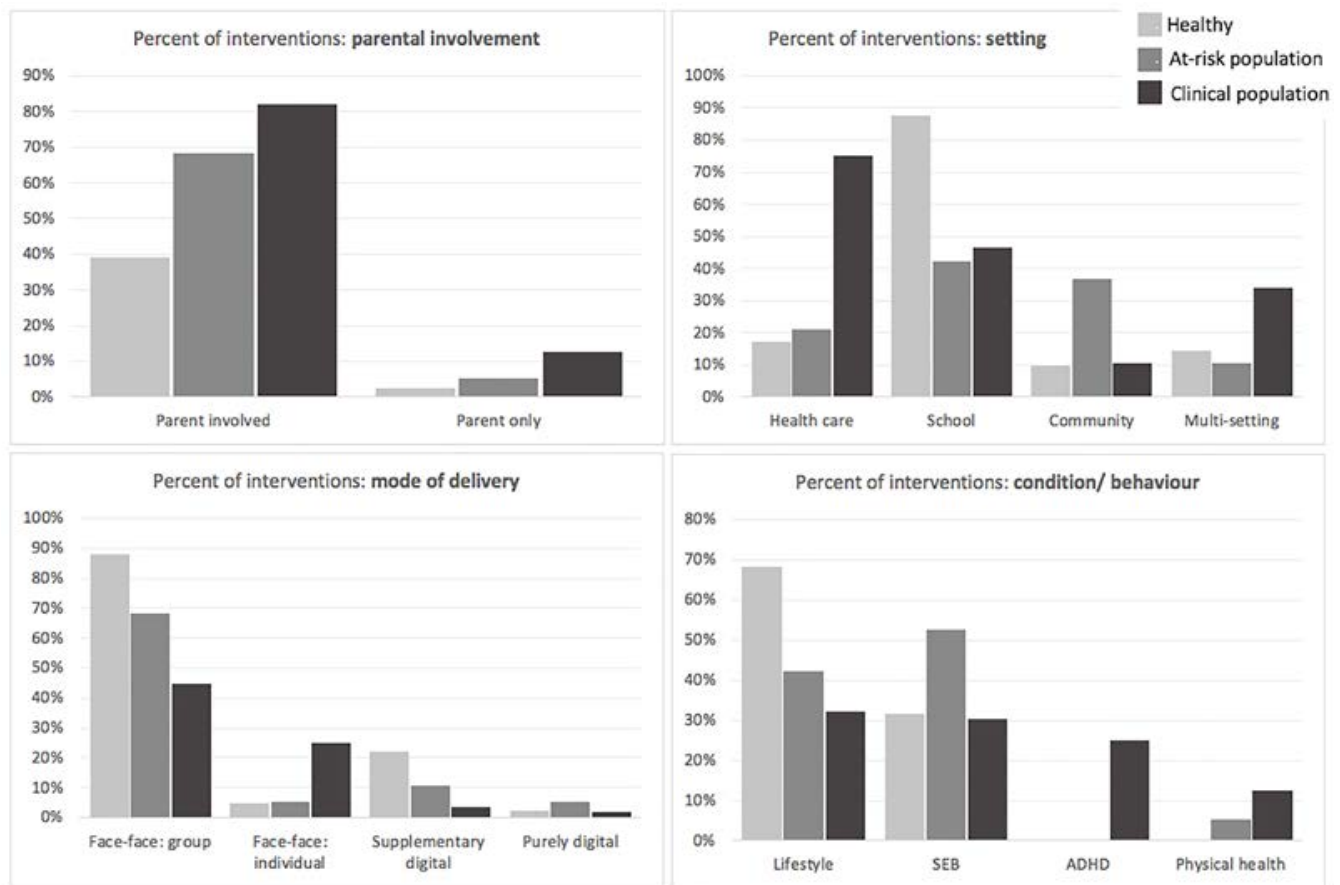

Figure 2 Characteristics of interventions, displayed by population. ADHD, attention deficit hyperactivity disorder; SEB, socialemotional-behavioural.

social and physical environment ${ }^{38-42}$; and providing reward and reinforcement, $29304043-45$ modelling ${ }^{32} 3639$ and a developmental rationale, that is, the child's limited cognitive capacity. ${ }^{46}$

Modality: 83 interventions $(70.9 \%)$ used a 'First Wave' behavioural approach, ${ }^{11} 51$ (43.6\%) used 'Second Wave' cognitive-behavioural approaches and 5 (4.3\%) used a 'Third Wave' approach. There were no 'Third Wave' interventions for younger children (5-7years old) (figure 3).
For some of the intervention components, the child was a passive recipient; the components were based on changing the environment around the child to change their behaviour. Twenty-five (21.4\%) used environmental restructuring (ie, changing the physical environment to change behaviour) including the provision of healthy foods, ${ }^{37} 3947-50$ sports sessions and equipment, ${ }^{37} 394151-54$ moving a TV out of the child's bedroom, ${ }^{55}$ provision of fluoride toothpaste ${ }^{56}$ and offering recreational activities. ${ }^{4857}$ Examples of structuring the social environment

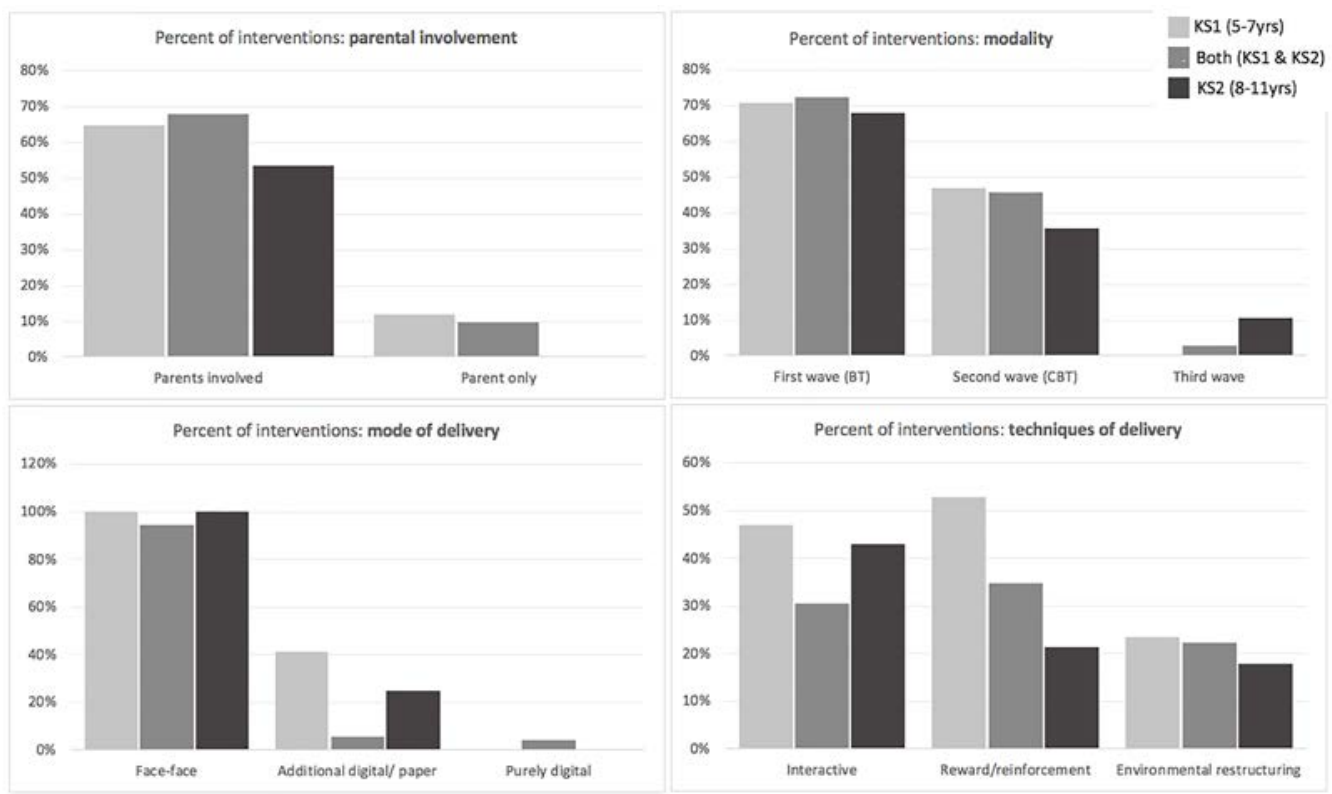

Figure 3 Characteristics of interventions, displayed by age. 
included activities designed to change the ecology of the classroom environment ${ }^{58}$ and activities changing the school-wide climate. ${ }^{59}$

Some intervention components required the child to be an active participant in therapy. ${ }^{44} 45$ 59-65 They were required to engage in the intervention through learning psychoeducational material, engaging in self-monitoring, self-regulation and self-management.

Intervention setting: 71 interventions $(60.7 \%)$ took place within a school setting. Fifty-three $(45.3 \%)$ took place in a clinical setting and $17(14.5 \%)$ took place in a community setting (including the fire service, police, girl guides/

Table 3 Use of interactive techniques in interventions

\begin{tabular}{|c|c|c|}
\hline \multicolumn{2}{|c|}{$\begin{array}{l}\text { Use of interactive techniques in } \\
\text { interventions }\end{array}$} & \multirow[b]{2}{*}{$\begin{array}{l}\text { Examples } \\
\text { "Zippy's Friends... interactive teaching methods including storytelling, discussion, modelling } \\
\text { and role playing"56 } \\
\text { "an audio-based cognitive-behavioural therapy (CBT) program for child anxiety disorders... } \\
\text { Children begin by joining six fictitious anxious children in the Turnaround adventure and are } \\
\text { educated on anxiety in an entertaining manner by these characters"59 } \\
\text { "curriculum in social-emotional learning... Each curriculum unit focuses on a specific grade- } \\
\text { appropriate children's book and begins with a book reading and discussion, ensuring that } \\
\text { students understand the primary themes of the story"87 } \\
\text { "Muck Monster... a metaphor for negative self-talk"72 } \\
\text { A Cognitive-Behavioral Pain Management Program called "Stop the pain with Happy-Pingu"58 } \\
\text { "Taming Sneaky Fears CBT Group Program manualized child treatment consisted of ... } \\
\text { stories, games, and activities designed specifically to teach cognitive-behavioral strategies"27 } \\
\text { "trauma narratives conveyed through storybooks with pictures created by students, "courage } \\
\text { cards' tailored to each student, use of published children's books to introduce certain } \\
\text { topics"74 }\end{array}$} \\
\hline $\begin{array}{l}\text { Narratives, } \\
\text { Storytelling } \\
\text { and } \\
\text { Characters }\end{array}$ & $\begin{array}{l}\text { Integrated into a } \\
\text { CBT programme }\end{array}$ & \\
\hline & $\begin{array}{l}\text { Characters as } \\
\text { stand-alone } \\
\text { interventions }\end{array}$ & $\begin{array}{l}\text { "a pictorial story about going to the dentist on pain perception, situational anxiety and } \\
\text { behavioral feedback during dental treatment"73 } \\
\text { "The child could carry out a version of the treatment (s)he had just undergone on the glove } \\
\text { puppet. The application of this behaviour management technique immediately after the dental } \\
\text { visit was used to enable the child to become active and so reduce anxiety"75 }\end{array}$ \\
\hline
\end{tabular}

\begin{tabular}{|c|c|c|}
\hline & $\begin{array}{l}\text { Games to Improve } \\
\text { Health Knowledge }\end{array}$ & $\begin{array}{l}\text { "'Top Grubs' a card game based on trumps with pictures of food, such that higher scoring } \\
\text { (trumping) foods are the healthier ones"90 } \\
\text { "An oral health education interventions involving 'contests on oral health knowledge",52 } \\
\text { "'Quiz time'... Review knowledge, understandings, and skills developed throughout the } \\
\text { program"91 }\end{array}$ \\
\hline $\begin{array}{l}\text { Group } \\
\text { interactive } \\
\text { activities }\end{array}$ & & $\begin{array}{l}\text { Group interventions used play, arts and game-based activities such as: } \\
\text { treasure hunts, material printing } \\
\text { puppet play, competitive games } \\
\text { map drawing and photographic techniques } \\
\text { ma } 93 \\
\text { and other unspecified games }\end{array}$ \\
\hline
\end{tabular}


Table 4 Dimensions of complexity

\begin{tabular}{|c|c|}
\hline Dimension of complexity & Examples \\
\hline $\begin{array}{l}\text { Multiple components } \\
\text { for different settings or } \\
\text { different recipients }\end{array}$ & $\begin{array}{l}\text { "cognitive-behavioral skills training, psychiatric consultation as needed, parent management training, } \\
\text { family therapy, school consultation, and peer interventions to encourage affiliation with prosocial } \\
\text { peers" } \\
\text { "parent and child groups; ... family counseling sessions... peer mentoring... academic tutoring"94 } \\
\text { "offered in the community, at home, school, at the treatment center"16 } \\
\text { "It aggregates adaptations of several treatments that have individually shown efficacy for ADHD } \\
\text { (parent training, teacher consultation/school-home notes, child skills training)"26 } \\
\text { "The therapist was in contact with the children, the parents, and the teachers in the weekly meetings } \\
\text { and by telephone. Likewise, the parents and teachers were in contact daily by means of the home- } \\
\text { school card",95 } \\
\text { "community-based ... team sports program... Home intervention to promote environmental } \\
\text { changes... Primary Care Counseling Intervention"33 }\end{array}$ \\
\hline $\begin{array}{l}\text { Multiple components for } \\
\text { the child }\end{array}$ & $\begin{array}{l}\text { "social-cognitive and emotional-coping skills training... peer-relations coaching... academic } \\
\text { tutoring... classroom management"96 } \\
\text { In other examples, the child's cognitive or behavioural therapy sessions were supplemented with an } \\
\text { additional experiential component such as sports sessions, }{ }^{33} 3748-506768 \text { cooking workshops }{ }^{36} 37 \text { or } \\
\text { field trips }\end{array}$ \\
\hline $\begin{array}{l}\text { Multiple components with } \\
\text { different modes of delivery }\end{array}$ & $\begin{array}{l}\text { "children were given a CD with relaxation exercises (PMR) to do as homework assignments" } 58 \\
\text { "online coaching was a three week programme (www.coaching-kidsprogram.com) providing parents } \\
\text { with materials and advice on how to encourage their children to brush their teeth" }\end{array}$ \\
\hline
\end{tabular}

ADHD, attention deficit hyperactivity disorder.

brownies and local gyms/recreation centres). Twentyseven $(23.1 \%)$ of all interventions, and $19(33.9 \%)$ of interventions for clinical populations, were delivered across multiple settings.

Mode of delivery: The most common mode of delivery was face-face $(n=113,96.6 \%)$, either in a group $(n=75)$, individual setting $(n=17)$, a mixture of both $(n=19)$, or group versus individual delivery as comparator arms in the RCT $(n=2)$. Three were purely digital interventions, and one was delivered via printed material. Fifty-four $(50 \%)$ included multiple modes of delivery; this included face-face with additional printed material $(n=26,22.2 \%)$ or additional digital components $(n=14,12.0 \%)$. Eightyseven $(74.4 \%)$ used some form of standardisation for the intervention delivery, including treatment protocols, manuals and session plans.

Techniques of delivery: 42 interventions included some form of play, arts, story and/or game-based technique (table 3 ); this equated to $39.3 \%$ of the interventions with a child recipient (ie, excluding those delivered to parents only).

Narratives, storytelling and characters were integrated into CBT programmes, used in behavioural/psychoeducational interventions, and two studies used stories or characters as stand-alone interventions. Forty interventions $(34.2 \%)$ used reward principles, and many implemented this in the form of a game; children could earn points, prizes, stickers and treats for adhering to the treatment plan. In most interventions, caregivers (parents, teachers) were responsible for structuring the reward system. ${ }^{66-69}$ Some interventions used quizzes and card games to promote knowledge about health behaviour or health management. This was either as a stand-alone intervention or within a multicomponent intervention.
Group activities were used to impart knowledge, ${ }^{40} 70-72$ teach skills, ${ }^{73}$ engage, ${ }^{74-76}$ and encourage interaction between group members. ${ }^{59}$

Many studies did not provide a rationale for including interactive techniques. In the cases where papers supplied a rationale, they stated that interactive techniques were developmentally appropriate, ${ }^{31}$ suited the child's stage of cognitive development, ${ }^{74} 77$ made concepts concrete, ${ }^{78}$ provided visual information, ${ }^{77}$ promoted communication, ${ }^{77}$ were more engaging, ${ }^{78}$ were tools for modelling behaviour ${ }^{6679}$ and were favourable for children's learning. ${ }^{74}$

Complexity: 70 interventions $(59.8 \%)$ were categorised as complex. The dimensions of complexity are summarised in table 4 .

\section{Effect of interventions}

Forty-eight papers failed to define a primary outcome, and a further 13 papers did not provide data on effectiveness/efficacy because they were RCT pilot studies, process evaluation studies or other types of paper which did not report effectiveness data. As such, we were able to assess the primary outcome for 56 interventions; of these, 26 interventions led to an improvement on the primary outcome, 23 did not lead to improvement on the primary outcome and 7 had mixed results (there was more than paper reporting on the intervention). Figure 4 displays the results of interventions with a primary outcome, presented by modality (note that an intervention may use more than one modality if it is multicomponent). There were a similar number of effective and non-effective behavioural interventions. We did not identify any effective third-wave interventions. 


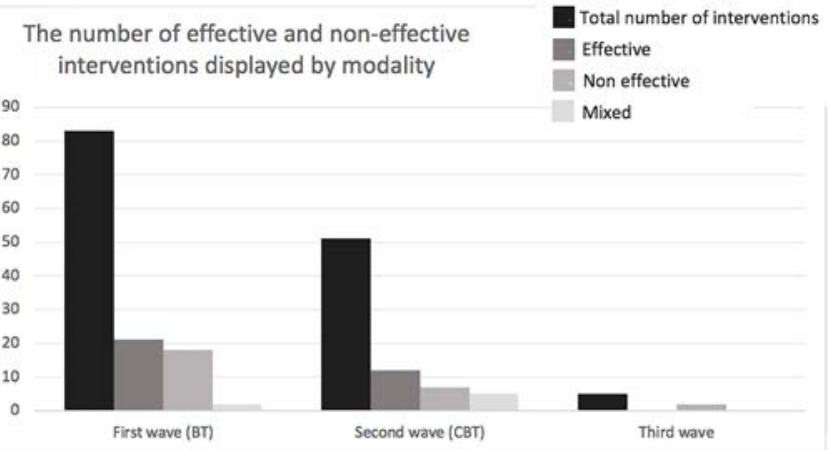

Figure 4 The number of effective and non-effective interventions, displayed by modality.

\section{DISCUSSION}

\section{Summary of findings}

This is the first systematic review to map and describe how behavioural interventions are delivered to children aged 5-11. Parental involvement in interventions was common $(64.1 \%)$. Many of the interventions were categorised as 'complex'18; they contained several components, included multiple modes of delivery, were delivered to more than one recipient and took place across different settings. This was particularly true for interventions delivered to clinical populations, where the majority were delivered to both the child and parent (78.7\%), and around a third $(33.9 \%)$ took place across multiple settings, typically a healthcare setting and school setting. Most (70.9\%) were 'First Wave' behavioural interventions, and few $(4.3 \%)$ were 'Third Wave'. Many of the interventions integrated interactive techniques. Purely digital and paper-based interventions were rare, but around a third used these tools as supplements to faceface delivery. There were potentially differences in interventions for younger (5-7years) and older (8-11 years) children; interventions for younger children tended to have more parental involvement (all of the clinical interventions for children aged 5-7years included parents), did not use 'Third Wave' approaches and more commonly used reward/reinforcement techniques. All interventions for older children involved the child as a recipient compared with $82.4 \%$ of the interventions for younger children. However, because of the small number of interventions for children 5-7years old, it is hard to draw firm conclusions.

\section{Strengths and limitations}

This review was not restricted to a specific health condition/behaviour. This allowed us to explore the principles of delivering interventions to younger children across a broad spectrum of health conditions/behaviours. We provided the interventions' modality (First, Second or Third Wave), but because of the size of the review it was not feasible to code specific techniques used in more detail, for example using the Behavioural Change Technique Taxonomy. ${ }^{12}$
We excluded observational cohort studies for pragmatic reasons; including observational studies to the data set would have made analyses unwieldy. While observational studies may have added some richness to the data, there were sufficient data in the RCTs to answer the research questions. Including only RCTs allowed us to focus on interventions most likely to be adopted into clinical care and those that were reported with higher quality. ${ }^{80}$ However, there was still wide variation in how interventions were reported, according to level of detail and terminology used. As such, there was a degree of subjectivity in data extraction of elements such as modality (eg, behavioural vs CBT) and standardisation (manualised vs non-manualised treatment). To mitigate this, we carried out independent double extraction, using established coding systems and taxonomies (for modality, ${ }^{11}$ mode of delivery, ${ }^{81}$ ages $^{82}$ and population type ${ }^{83}$ ) and developed additional guidance documents.

This study was primarily designed to describe the characteristics of the interventions. We do present some data about the efficacy of these interventions; however, we cannot draw strong interpretations from this as we only reviewed primary outcomes (unavailable for $40 \%$ of the studies) and we did not carry out quality assessment.

\section{Implications in context of literature}

When designing and delivering interventions for children, they should be developmentally sensitive ${ }^{142222}$ and rooted in developmental theory. Theory on cognitive development states that children tend to be limited to concrete rather than abstract thought, ${ }^{13}$ as well as less sophisticated illness beliefs. ${ }^{23}$ As such, concrete interventions focused on behavioural recommendations are more appropriate. ${ }^{24}$ Consistent with this, behavioural interventions were most common, though we did find that a similar number of effective and non-effective behavioural interventions. CBT requires logical analysis and abstract thinking, and there are caveats on how this should be used with children. ${ }^{13}$ We found fewer CBT-based therapies. There were only five third-wave interventions, and none were delivered to children under the age of 7 . The limited use of these approaches is consistent with existing literature stating that third-wave approaches may not be appropriate for children, ${ }^{3}$ and concepts such as metacognition are likely to be beyond the cognitive capacities of this younger population. Alternatively, the low number of papers may be because this is a relatively new approach with children; research is in its early stages but is gaining interest, with examples of RCTs currently underway. ${ }^{4}$ The papers included in this review suggest it may be possible to adapt third-wave concepts, to make them developmentally appropriate for younger children, using exercises, visuals, characters and drawing to make these abstract concepts more concrete, as well as providing briefer interventions. ${ }^{5}$ From the few studies in this review, we did not identify any effective third-wave interventions. At this stage, third-wave approaches for children are novel and untested, but worthy of more investigation to evaluate 
effectiveness, and explore how they can be delivered to children in a developmentally sensitive way.

Interactive methods are suited to the cognitive developmental stage of children 5-11 years old. Children can find it difficult to process abstract information and express themselves verbally. ${ }^{13} 84$ Art-based methods can provide an opportunity to communicate visually, ${ }^{85}$ likewise stories can include visual supports and are engaging for children. ${ }^{86}$ Play is an important part of childhood; it is enjoyable, rewarding, and can support children to learn skills and behaviours. ${ }^{87}$ Many interventions reviewed here used arts, play and games-based techniques to engage and teach children. Developmental theory also highlights the importance of caregivers; in childhood, caregivers play a key role in structuring the child's environment and shaping the child's behaviour. ${ }^{2488}$ Children are embedded in the family context. Equally, children may spend many hours a day at school in the care of teachers. In this review, many studies included parents and schools, and parental involvement was greatest for the younger children.

Although many interventions included in this review appeared informed by developmental theories, many did not explicitly report how developmental theory guided intervention design. Intervention development and reporting would be improved by doing so.

In this review, there are many examples of interventions which target the same behaviour/condition for similar populations but have been developed independently. However, guidance for developing interventions recommends using a systematic review to identify existing evidence-based interventions, ${ }^{18}$ and refining these to investigate optimal delivery, rather than developing a novel one.

This review highlights issues about trial design in this field. A clearly defined and pre-specified primary outcome is important; it reduces the risks of selective reporting of outcomes and false-positive from analysing too many outcomes. ${ }^{6}$ However, we found that around $40 \%$ of the interventions failed to specify a primary outcome.

\section{Future research}

Tools to aid the design and reporting of interventions do not sufficiently capture characteristics important for delivery to children; the Behaviour Change Techniques Taxonomy ${ }^{12}$ does not sufficiently cover interactive techniques or delivery via parent proxies. Future work to incorporate these techniques may enhance these tools.

In this mapping review, we identified areas of interest around parental involvement, the use of digital interventions to supplement face-face delivery and setting (delivery in both school and clinics). Future systematic reviews could focus on these areas.

Acknowledgements The corresponding author wishes to thank Catherine Borwik (University to Bristol, Information Specialist) for helping develop the search strategy.

Contributors $\mathrm{AB}$ conceptualised the study as part of a $\mathrm{PhD}$ program, drafted the protocol, created the search strategy, screened papers and carried out data extraction, drafted the manuscript, approved the final manuscript as submitted and agree to be accountable for all aspects of the work. RMP drafted the protocol for the study, screened papers and carried out data extraction, critically reviewed the manuscript, and approved the final manuscript as submitted and agree to be accountable for all aspects of the work. CL screened papers and carried out data extraction, critically reviewed the manuscript, and approved the final manuscript as submitted and agree to be accountable for all aspects of the work. NH-S screened papers and carried out data extraction, critically reviewed the manuscript, and approved the final manuscript as submitted and agree to be accountable for all aspects of the work. RR screened papers and carried out data extraction, critically reviewed the manuscript, and approved the final manuscript as submitted and agree to be accountable for all aspects of the work. ML provided supervision of data collection and analysis, critically reviewed the manuscript, and approved the final manuscript as submitted and agree to be accountable for all aspects of the work. AD drafted the protocol for the study, provided supervision of data collection and analysis, critically reviewed the manuscript, and approved the final manuscript as submitted and agree to be accountable for all aspects of the work. SS screened papers and carried out data extraction, critically reviewed the manuscript, and approved the final manuscript as submitted and agree to be accountable for all aspects of the work. LB drafted the protocol for the study, screened papers and carried out data extraction, critically reviewed the manuscript, and approved the final manuscript as submitted and agree to be accountable for all aspects of the work. RM drafted the protocol for the study, provided supervision of data collection and analysis, critically reviewed the manuscript, and approved the final manuscript as submitted and agree to be accountable for all aspects of the work. SY screened papers and carried out data extraction, critically reviewed the manuscript, and approved the final manuscript as submitted and agree to be accountable for all aspects of the work. EC drafted the protocol, created the search strategy, provided supervision of data collection and analysis, critically reviewed the manuscript, and approved the final manuscript as submitted and agree to be accountable for all aspects of the work

Funding $A B$ is funded by the National Institute for Health Research (Doctoral Research Fellowship, DRF-2017-10-169). EC is funded by the National Institute for Health Research (Senior Research Fellowship, SRF-2013-06-013).

Disclaimer The views expressed in this publication are those of the authors and not necessarily those of the NHS, the National Institute for Health Research or the Department of Health.

Competing interests None declared.

Patient consent for publication Not required.

Provenance and peer review Not commissioned; externally peer reviewed.

Data availability statement All the data relevant to the study are included in the article or uploaded as supplementary information.

Open access This is an open access article distributed in accordance with the Creative Commons Attribution Non Commercial (CC BY-NC 4.0) license, which permits others to distribute, remix, adapt, build upon this work non-commercially, and license their derivative works on different terms, provided the original work is properly cited, appropriate credit is given, any changes made indicated, and the use is non-commercial. See: http://creativecommons.org/licenses/by-nc/4.0/.

ORCID iDs

Amberly Brigden http://orcid.org/0000-0002-7958-7881

Esther Crawley http://orcid.org/0000-0002-2521-0747

\section{REFERENCES}

1 Turner-Cobb J. Child health psychology: a biopsychosocial perspective. SAGE, 2013.

2 Marmot M. Fair society, healthy lives: the Marmot Review: strategic review of health inequalities in England post-2010 2010.

3 Galobardes B, Smith GD, Lynch JW. Systematic review of the influence of childhood socioeconomic circumstances on risk for cardiovascular disease in adulthood. Ann Epidemiol 2006;16:91-104.

4 Kessler RC, McLaughlin KA, Green JG, et al. Childhood adversities and adult psychopathology in the WHO World Mental Health Surveys. Br J Psychiatry 2010;197:378-85.

5 Wadsworth MEJ, Kuh DJL. Childhood influences on adult health: a review of recent work from the British 1946 national birth cohort study, the MRC national survey of health and development. Paediatr Perinat Epidemiol 1997;11:2-20. 
6 Wright CM, Parker L, Lamont D, et al. Implications of childhood obesity for adult health: findings from thousand families cohort study. BMJ 2001;323:1280-4.

7 Langford R, Bonell C, Jones $\mathrm{H}$, et al. The World Health Organization's Health Promoting Schools framework: a Cochrane systematic review and meta-analysis. BMC Public Health 2015:15:130

8 National Institute for Health and Care Excellence. Physical activity for children and young people, 2009. Available: https://www.nice. org.uk/guidance/ph17

9 National Institute for Health and Care Excellence. Diabetes (type 1 and type 2) in children and young people: diagnosis and management, 2015. Available: https://www.nice.org.uk/guidance/ ng18

10 National Institute for Health and Care Excellence. Depression in children and young people: identification and management, 2005. Available: https://www.nice.org.uk/guidance/ng134

11 Kahl KG, Winter L, Schweiger U. The third wave of cognitive behavioural therapies: what is new and what is effective? Curr Opin Psychiatry 2012;25:522-8.

12 Michie S, Richardson M, Johnston M, et al. The behavior change technique taxonomy (V1) of 93 hierarchically clustered techniques: building an international consensus for the reporting of behavior change interventions. Ann Behav Med 2013:46:81-95.

13 Grave J, Blissett J. Is cognitive behavior therapy developmentally appropriate for young children? A critical review of the evidence. Clin Psychol Rev 2004;24:399-420.

14 Bogosian A, Van Vliet LM, Craig G, et al. Minding the gap and moving forward in children's long-term conditions: a vital role for health psychology. Br J Health Psychol 2016;21:493-8.

15 Schneider S, Blatter-Meunier J, Herren C, et al. Disorder-specific cognitive-behavioral therapy for separation anxiety disorder in young children: a randomized waiting-list-controlled trial. Psychother Psychosom 2011;80:206-15.

16 Koegl CJ, Farrington DP, Augimeri LK, et al. Evaluation of a targeted cognitive-behavioral program for children with conduct problemsthe SNAP® under 12 outreach project: service intensity, age and gender effects on short- and long-term outcomes. Clin Child Psychol Psychiatry 2008;13:419-34.

17 Robinson PD, Oberoi S, Tomlinson D, et al. Management of fatigue in children and adolescents with cancer and in paediatric recipients of haemopoietic stem-cell transplants: a clinical practice guideline. Lancet Child Adolesc Health 2018;2:371-8.

18 Craig P, Dieppe P, Macintyre S, et al. Developing and evaluating complex interventions: the new Medical Research Council guidance. Int J Nurs Stud 2013;50:587-92.

19 Michie S, van Stralen MM, West R. The behaviour change wheel: a new method for characterising and designing behaviour change interventions. Implementation Sci 2011;6.

20 Bartholomew LK, Parcel GS, Kok G, et al. Planning health promotion programs: an intervention mapping approach. John Wiley \& Sons, 2011.

21 Wight $\mathrm{D}$, Wimbush $\mathrm{E}$, Jepson $\mathrm{R}$, et al. Six steps in quality intervention development (6SQuID). J Epidemiol Community Health 2016;70:520-5.

22 Pai ALH, McGrady M. Systematic review and meta-analysis of psychological interventions to promote treatment adherence in children, adolescents, and young adults with chronic illness. $J$ Pediatr Psychol 2014;39:918-31.

23 Koopman HM, Baars RM, Chaplin J, et al. Illness through the eyes of the child: the development of children's understanding of the causes of illness. Patient Educ Couns 2004;55:363-70.

24 Erickson SJ, Gerstle M, Feldstein SW. Brief interventions and motivational interviewing with children, adolescents, and their parents in pediatric health care settings. Arch Pediatr Adolesc Med 2005;159:1173-80.

25 Tarpey S, Caes L, Heary C. Supporting children with chronic pain in school: understanding teachers' experiences of pain in the classroom. Eur Health Psychol 2018;20:419-24.

26 Miake-Lye IM, Hempel S, Shanman R, et al. What is an evidence map? A systematic review of published evidence maps and their definitions, methods, and products. Syst Rev 2016;5:28.

27 Covidence. World-class systematic review management, 2013. Available: https://www.covidence.org/

28 Moher D, Liberati A, Tetzlaff J, et al. Preferred reporting items for systematic reviews and meta-analyses: the PRISMA statement. $B M J$ 2009;339:b2535.

29 Golan M, Kaufman V, Shahar DR. Childhood obesity treatment: targeting parents exclusively $v$. parents and children. Br J Nutr 2006;95:1008-15.
30 Pfiffner LJ, Hinshaw SP, Owens E, et al. A two-site randomized clinical trial of integrated psychosocial treatment for ADHDinattentive type. J Consult Clin Psychol 2014;82:1115-27.

31 Monga S, Rosenbloom BN, Tanha A, et al. Comparison of childparent and parent-only cognitive-behavioral therapy programs for anxious children aged 5 to 7 years: short- and long-term outcomes. J Am Acad Child Adolesc Psychiatry 2015;54:138-46.

32 levers-Landis CEet al. A randomized controlled trial for the primary prevention of osteoporosis among preadolescent girl scouts: 1-year outcomes of a behavioral program. J Pediatr Psychol 2005;30:155-65.

33 Bernstein GA, Layne AE, Egan EA, et al. School-based interventions for anxious children. J Am Acad Child Adolesc Psychiatry 2005;44:1118-27.

34 Bernstein GA, Bernat DH, Victor AM, et al. School-based interventions for anxious children: 3-, 6-, and 12-month follow-ups. $J$ Am Acad Child Adolesc Psychiatry 2008;47:1039-47.

35 O'Connor TM, Hilmers A, Watson K, et al. Feasibility of an obesity intervention for paediatric primary care targeting parenting and children: helping hand. Child Care Health Dev 2013;39:141-9.

36 Habib-Mourad C, Ghandour LA, Moore HJ, et al. Promoting healthy eating and physical activity among school children: findings from Health-E-PALS, the first pilot intervention from Lebanon. BMC Public Health 2014;14:940.

37 Robinson TN, Matheson D, Desai M, et al. Family, community and clinic collaboration to treat overweight and obese children: Stanford GOALS - a randomized controlled trial of a three-year, multicomponent, multi-level, multi-setting intervention. Contemp Clin Trials 2013;36:421-35.

38 Dorn LD, Kolko DJ, Shenk CE, et al. Influence of treatment for disruptive behavior disorders on adrenal and gonadal hormones in youth. J Clin Child Adolesc Psychol 2011;40:562-71.

39 Elder JP, Crespo NC, Corder K, et al. Childhood obesity prevention and control in city recreation centres and family homes: the MOVE/ me Muevo project. Pediatr Obes 2014;9:218-31.

40 French SA, Story M, Fulkerson JA, et al. Increasing weight-bearing physical activity and calcium-rich foods to promote bone mass gains among 9-11 years old girls: outcomes of the Cal-Girls study. Int $J$ Behav Nutr Phys Act 2005;2.

41 Clarke JL, Griffin TL, Lancashire ER, et al. Parent and child perceptions of school-based obesity prevention in England: a qualitative study. BMC Public Health 2015;15:1224.

42 Marcus C, Nyberg G, Nordenfelt A, et al. A 4-year, clusterrandomized, controlled childhood obesity prevention study: STOPP. Int J Obes 2009;33:408-17.

43 Abikoff $\mathrm{H}$, Gallagher R, Wells KC, et al. Remediating organizational functioning in children with ADHD: immediate and long-term effects from a randomized controlled trial. J Consult Clin Psychol 2013:81:113-28.

44 Döpfner M, Ise E, Wolff Metternich-Kaizman T, et al. Adaptive multimodal treatment for children with attention-deficit-/hyperactivity disorder: an 18 month follow-up. Child Psychiatry Hum Dev 2015;46:44-56

45 Lipman EL, Boyle MH, Cunningham C, et al. Testing effectiveness of a community-based aggression management program for children 7 to 11 years old and their families. J Am Acad Child Adolesc Psychiatry 2006;45:1085-93.

46 Nyberg G, Norman Åsa, Sundblom E, et al. Effectiveness of a universal parental support programme to promote health behaviours and prevent overweight and obesity in 6-year-old children in disadvantaged areas, the Healthy School Start Study II, a clusterrandomised controlled trial. Int J Behav Nutr Phys Act 2016;13.

47 Sahota P, Rudolf MC, Dixey R, et al. Randomised controlled trial of primary school based intervention to reduce risk factors for obesity. BMJ 2001;323:1029-32.

48 Ayala GX, Elder JP, Campbell NR, et al. Longitudinal intervention effects on parenting of the Aventuras para Niños study. Am J Prev Med 2010;38:154-62.

49 Anderson AS, Porteous LEG, Foster E, et al. The impact of a school-based nutrition education intervention on dietary intake and cognitive and attitudinal variables relating to fruits and vegetables. Public Health Nutr 2005;8:650-6.

50 Golley R, Baines E, Bassett P, et al. School lunch and learning behaviour in primary schools: an intervention study. Eur J Clin Nutr 2010;64:1280-8.

51 Yildırım M, Arundell L, Cerin E, et al. What helps children to move more at school recess and lunchtime? Mid-intervention results from Transform-Us! cluster-randomised controlled trial. Br J Sports Med 2014;48:271-7.

52 Sharifah WW, Nur HH, Ruzita AT, et al. The Malaysian childhood obesity treatment trial (MASCOT). Malays J Nutr 2011;17:229-36. 
53 Angelopoulos PD, Milionis HJ, Grammatikaki E, et al. Changes in $\mathrm{BMI}$ and blood pressure after a school based intervention: the children study. The European Journal of Public Health 2009;19:319-25.

54 Barkin SL, Gesell SB, Póe EK, et al. Changing overweight Latino preadolescent body mass index: the effect of the parent-child dyad. Clin Pediatr 2011:50:29-36

55 Crespo NC, Elder JP, Ayala GX, et al. Results of a multi-level intervention to prevent and control childhood obesity among Latino children: the Aventuras para Niños study. Ann Behav Med 2012;43:84-100.

56 Tai B-J, Jiang H, Du M-Q, et al. Assessing the effectiveness of a school-based oral health promotion programme in Yichang City, China. Community Dent Oral Epidemiol 2009;37:391-8.

57 Taussig HN, Culhane SE, Garrido E, et al. RCT of a mentoring and skills group program: placement and permanency outcomes for foster youth. Pediatrics 2012;130:e33-9.

58 Schonert-Reichl KA, Oberle E, Lawlor MS, et al. Enhancing cognitive and social-emotional development through a simple-to-administer mindfulness-based school program for elementary school children: a randomized controlled trial. Dev Psychol 2015;51:52-66.10.1037/ a0038454

59 Snyder FJ, Acock AC, Vuchinich S, et al. Preventing negative behaviors among elementary-school students through enhancing students' social-emotional and character development. Am J Health Promot 2013;28:50-8.

60 Clarke AM, Bunting B, Barry MM. Evaluating the implementation of a school-based emotional well-being programme: a cluster randomized controlled trial of Zippy's friends for children in disadvantaged primary schools. Health Educ Res 2014;29:786-98.

61 Downs JA, Roberts CM, Blackmore AM, et al. Benefits of an education programme on the self-management of aerosol and airway clearance treatments for children with cystic fibrosis. Chron Respir Dis 2006;3:19-27.

62 Groß M, Warschburger P. Evaluation of a cognitive-behavioral pain management program for children with chronic abdominal pain: a randomized controlled study. Int J Behav Med 2013;20:434-43.

63 Infantino A, Donovan CL, March S. A randomized controlled trial of an audio-based treatment program for child anxiety disorders. Behav Res Ther 2016;79:35-45.

64 Stallard P, Skryabina E, Taylor G, et al. Classroom-Based cognitive behaviour therapy 0: a cluster randomised controlled trial to prevent anxiety in children through education in schools (PACES). Lancet Psychiatry 2014;1:185-92.

65 Waters AM, Groth TA, Sanders M, et al. Developing partnerships in the provision of youth mental health services and clinical education: a school-based cognitive behavioral intervention targeting anxiety symptoms in children. Behav Ther 2015;46:844-55

66 Hurling R, Claessen JP, Nicholson J, et al. Automated coaching to help parents increase their children's brushing frequency: an exploratory trial. Community Dent Health 2013;30:88-93.

67 Kellam SG, Wang W, Mackenzie ACL, et al. The impact of the good behavior game, a universal classroom-based preventive intervention in first and second grades, on high-risk sexual behaviors and drug abuse and dependence disorders into young adulthood. Prev Sci 2014;15:6-18

68 Menting B, Koot $\mathrm{H}$, Lier P. Peer acceptance and the development of emotional and behavioural problems: results from a preventive intervention study. Int J Behav Dev 2015;39:530-40.

69 Poduska JM, Kellam SG, Wang W, et al. Impact of the good behavior game, a universal classroom-based behavior intervention, on young adult service use for problems with emotions, behavior, or drugs or alcohol. Drug Alcohol Depend 2008;95:S29-44.

70 Murry VM, Berkel C, Brody GH, et al. The strong African American families program: longitudinal pathways to sexual risk reduction. $J$ Adolesc Health 2007;41:333-42.

71 Chen JL, Weiss S, Heyman MB, et al. Efficacy of a child-centred and family-based program in promoting healthy weight and healthy behaviors in Chinese American children: a randomized controlled study. J Public Health 2010;32:219-29.

72 Chen J-L, Weiss SJ, Heyman MB, et al. The active balance childhood program for improving coping and quality of life in Chinese American children. Nurs Res 2010;59:270-9.

73 Rooney R, Hassan S, Kane R, et al. Reducing depression in 9-10 year old children in low SES schools: a longitudinal universal randomized controlled trial. Behav Res Ther 2013;51:845-54.
74 Kalavainen MP, Korppi MO, Nuutinen OM. Clinical efficacy of groupbased treatment for childhood obesity compared with routinely given individual counseling. Int J Obes 2007;31:1500-8.

75 Lau W-yee, Chan CK-ying, Li JC-hong, et al. Effectiveness of group cognitive-behavioral treatment for childhood anxiety in community clinics. Behav Res Ther 2010;48:1067-77.

76 Martinsen KD, Kendall PC, Stark K, et al. Prevention of anxiety and depression in children: acceptability and feasibility of the transdiagnostic emotion program. Cogn Behav Pract 2016;23:1-13.

77 Aminabadi NA, Vafaei A, Erfanparast L, et al. Impact of pictorial story on pain perception, situational anxiety and behavior in children: a cognitive-behavioral schema. J Clin Pediatr Dent 2011;36:127-32.

78 Langley AK, Gonzalez A, Sugar CA, et al. Bounce back: effectiveness of an elementary school-based intervention for multicultural children exposed to traumatic events. J Consult Clin Psychol 2015;83:853-65.

79 Howard KE, Freeman R. An evaluation of the PalS after treatment modelling intervention to reduce dental anxiety in child dental patients. Int J Paediatr Dent 2009;19:233-42.

80 Hoffmann T, English T, Glasziou P. Reporting of interventions in randomised trials: an audit of journal Instructions to authors. Trials 2014;15:20

81 Carey RN, Evans F, Horan M, et al. Mode of delivery of behaviour change interventions taxonomy version 0 (MoDTv0) 2016.

82 Education Df. The national curriculum in England: key stages 1 and 2 framework document. Available: https://assets. publishing.service. gov.uk/government/uploads/system/uploads/attachment_data/file/ 425601/PRIMARY_national_curriculum.pdf2013

83 Mrazek PJ, Haggerty RJ. Reducing risks for mental disorders: frontiers for preventive intervention research. Washington, DC: National Academy Press, 1994

84 Hill M, Laybourn A, Borland M. Engaging with primary-aged children about their emotions and well-being: methodological considerations. Children and Society 1996;10:129-44.

85 Coad J. Using art-based techniques in engaging children and young people in health care consultations and/or research. $J$ Res Nurs 2007:12:487-97.

86 Spencer TD, Kajian M, Petersen DB, et al. Effects of an individualized narrative intervention on children's storytelling and comprehension skills. J Early Interv 2013;35:243-69.

87 Nijhof SL, Vinkers CH, van Geelen SM, et al. Healthy play, better coping: the importance of play for the development of children in health and disease. Neurosci Biobehav Rev 2018;95:421-9.

88 Bronfenbrenner U. The ecology of human development: experiments by nature and design. Cambridge, MA: Harvard University Press, 1979.

89 So CYC, Leung PWL, Hung S-F. Treatment effectiveness of combined medication/behavioural treatment with Chinese ADHD children in routine practice. Behav Res Ther 2008;46:983-92.

90 Kipping RR, Howe LD, Jago R, et al. Effect of intervention aimed at increasing physical activity, reducing sedentary behaviour, and increasing fruit and vegetable consumption in children: active for life year 5 (AFLY5) school based cluster randomised controlled trial. BMJ 2014;348:g3256.

91 Pophillat E, Rooney RM, Nesa M, et al. Preventing internalizing problems in 6-8 year old children: a universal school-based program. Front Psychol 2016;7:1928.

92 Salmon J, Ball K, Crawford D, et al. Reducing sedentary behaviour and increasing physical activity among 10 -year-old children: overview and process evaluation of the 'Switch-Play' intervention. Health Promot Int 2005;20:7-17.

93 Salmon J, Ball K, Hume C, et al. Outcomes of a group-randomized trial to prevent excess weight gain, reduce screen behaviours and promote physical activity in 10-year-old children: Switch-Play. Int J Obes 2008;32:601-12.

94 Burke JD, Loeber R. Mechanisms of behavioral and affective treatment outcomes in a cognitive behavioral intervention for boys. $J$ Abnorm Child Psychol 2016;44:179-89.

95 Miranda A, Presentación MJ, Siegenthaler R, et al. Effects of a psychosocial intervention on the executive functioning in children with ADHD. J Learn Disabil 2013;46:363-76.

96 Carré JM, Iselin A-MR, Welker KM, et al. Testosterone reactivity to provocation mediates the effect of early intervention on aggressive behavior. Psychol Sci 2014;25:1140-6.

97 Stockton MB, McClanahan BS, Lanctot JQ, et al. Identification of facilitators and barriers to participation in weight gain prevention research by African American girls. Contemp Clin Trials 2012;33:38-45. 